\title{
PREDIKSI DATA TRANSAKSI PENJUALAN TIME SERIES MENGGUNAKAN REGRESI LSTM
}

\author{
Marie Luthfi Ashari ${ }^{1}$, Mujiono Sadiki ${ }^{2}$ \\ 1,2 Jurusan Teknik Informatika, Fakultas IImu Komputer, \\ Universitas Mercu Buana \\ Jakarta, Indonesia
}

e-mail: 41515110115@student.mercubuana.ac.id ${ }^{1}$, mujiono@mercubuana.ac.id²

\begin{abstract}
Abstrak
Sebagai upaya untuk memenangkan persaingan di pasar, perusahaan farmasi harus menghasilkan produk obat - obatan yang berkualitas. Untuk menghasilkan produk yang berkualitas, diperlukan perencanaan produksi yang baik dan efisien. Salah satu dasar perencanaan produksi adalah prediksi penjualan. PT. Metiska Farma telah menerapkan metode prediksi dalam proses produksi, akan tetapi prediksi yang dihasilkan tidak akurat sehingga menyebabkan tidak optimal dalam memenuhi permintaan pasar. Untuk meminimalisir masalah kurang akuratnya proses prediksi tersebut, dalam penelitian yang disajikan pada makalah ini dilakukan uji coba prediksi menggunakan teknik Machine Learning dengan metode Regresi Long Short Term Memory (LSTM). Teknik yang diusulkan diuji coba menggunakan dataset penjualan produk "X" dari PT. Metiska Farma dengan parameter kinerja Root Mean Squared Error (RMSE) dan MAPE (Mean Absolute Percentage Error). Hasil penelitian ini berupa nilai rata - rata evaluasi error dari pemodelan data training dan data testing. Di mana hasil menunjukan bahwa Regresi LSTM memiliki nilai prediksi penjualan dengan evaluasi model melalui RMSE sebesar 286.465.424 untuk data training dan 187.013.430 untuk data testing. Untuk nilai MAPE sebesar $787 \%$ dan $309 \%$ untuk data training dan data testing secara berurut.
\end{abstract}

Kata kunci: Machine Learning, Time Prediction, Lstm for Regression, Lstm

\begin{abstract}
In striving to win for competition in the market, pharmaceutical companies must produce quality pharmaceutical products. To produce a quality product, good and efficient production planning is needed. One basis for production planning is the sale prediction. PT. Metiska Farma has applied the prediction method in the production process, but the predictions resulted are not so accurate that the fulfillment of market demand is not optimal. To minimize the inaccuracy in prediction process, this research conducted an experiment of prediction using Machine Learning technique with the Long Short Term Memory (LSTM) regression method. The proposed technique used in the experiment was "X" product sales dataset from PT. Metiska Farma with performance parameters of Root Mean Squared Error (RMSE) and MAPE (Mean Absolute Percentage Error). The results of this research were in the form of average error evaluation value from the modeling of data training and data testing. The results indicated that LSTM regression had a sales prediction value with evaluation model through RMSE of 286,465,424 for data training and of $187,013,430$ for data testing. Meanwhile, MAPE value was $787 \%$ and $309 \%$ for data training and data testing respectively.
\end{abstract}

Keywords : Machine Learning, Time Prediction, Lstm for Regression, Lstm 


\section{PENDAHULUAN}

PT. Metiska Farma merupakan perusahaan yang bergerak di bidang industri farmasi. Produk yang dihasilkan oleh perusahaan ini adalah produk obat obatan berjenis ethical penjualannya tidak dilakukan secara bebas namun harus menggunakan resep dokter. Dalam mempromosikan produk - produk ethicalnya PT. Metiska Farma menggunakan medical representative sebagai media penjualan. Dengan berhasilnya medical representative dalam mempromosikan dan menjual produk yang ditawarkan kepada user, maka perusahaan mendapatkan nilai hasil penjualan atau data penjualan.

Peramalan merupakan suatu proses untuk memprediksi keadaan yang akan terjadi pada masa yang akan datang berdasarkan data yang sudah ada. Contoh peramalan misalnya hasil penjualan yang digunakan untuk menentukan besarnya perkiraan volume penjualan sehingga dapat diperoleh keputusan yang tepat berdasarkan data yang sudah ada [1]. Peramalan penjualan (forecasting) memegang peranan yang sangat penting dalam perencanaan dan pengambilan keputusan khususnya di bidang produksi dalam industri farmasi. Aktivitas manajemen produksi dan operasi menggunakan peramalan permintaan dalam perencanaan yang menyangkut perencanaan produksi.

Peramalan penjualan yang buruk, secara otomatis akan menyebabkan perencanaan produksi yang buruk. Akibatnya inventaris menjadi sangat tinggi atau sebaliknya, hilangnya penjualan karena tidak tersedia barang yang akan dijual. Inventaris yang terlalu tinggi mengakibatkan bertambahnya biaya yang disebabkan sumber daya yang ada menjadi tidak efisien. Pada kondisi sebaliknya, akan menyebabkan terjadinya kekosongan produk di pasaran. Kondisi ini menciptakan peluang bagi pesaing (kompetitor) untuk masuk, sehingga mengakibatkan hilangnya peluang pasar yang ada (loss opportunity) [2].

PT. Metiska Farma telah melakukan forecasting pada tahap perencanaan produksi namun hasil dari peramalan tidak akurat karena dilakukan secara manual. Hal tersebut dapat menyebabkan keadaan inventaris tinggi atau keadaan sebaliknya mungkin terjadi. Pada penelitian yang dilakukan untuk mengatasi masalah tersebut dilakukan eksperimen prediksi berbasis Machine Learning menggunakan teknik Regresi Long Short Term Memory (LSTM). Dengan menggunakan data penjualan obat "X" dari PT. Metiska Farma peramalan dilakukan menggunakan teknik Regresi Long Short Term Memory. Setiap instan data mengandung dua atribut yaitu tanggal penjualan dan value penjualan yang tergolong ke dalam data time series.

Long Short Term Memory (LSTM) adalah turunan dari Recurrent Neural Network (RNN) yang terbukti berhasil digunakan untuk prediksi data time series [3]. RNN mampu menggunakan informasi yang telah direkam sebelumnya yang panjang urutannya atau sequence nya beragam. RNN memiliki masalah vanishing gradient oleh karena itu, pembangunan sistem ini dibuat dengan metode Regresi LSTM.

Penggunaan LSTM dengan koreksi kesalahan berdasarkan dukungan vektor regresi digunakan untuk mewujudkan prediksi time series, karena parameter model LSTM yang terlatih tidak dapat diperbarui [4]. Metode regresi adalah metode statistik matematika yang paling umum digunakan. Regresi digunakan untuk berurusan dengan korelasi antar variable adalah kunci atau alat untuk menguji hubungan data. Mempertimbangkan faktor kesalahan, pendekatan regresi dapat menggambarkan hubungan antar variabel [5]. 
Peramalan dibuat diupayakan agar dapat meminimalisir pengaruh ketidakpastian terhadap sebuah masalah. Dengan kata lain peramalan bertujuan mendapatkan peramalan yang bisa meminimalisir kesalahan meramal (forecast error) [6]. Penghitung indikator dalam mengevaluasi kinerja prediksi yang digunakan dalam penelitian ini adalah Root mean squared error (RMSE) [7].

Metode Regresi Long Short Term Memory (LSTM) dalam memprediksi sudah ada beberapa peneliti yang telah melakukan studi. Berikut disajikan beberapa studi yang telah melakukan prediksi menggunakan metode yang diusulkan. Biasanya digunakan untuk menyelesaikan beberapa masalah prediksi seperti penelitian di bawah ini.

Pertama, penelitian yang telah dilakukan oleh Ahmad Ashril Rizal dan Siti Soraya mengenai prediksi kunjungan wisatawan mancanegara di pulau Lombok [8]. Masalah dalam kasus ini adalah memprediksi kunjungan wisatawan pada bulan berikutnya dengan data yang diberikan tiap bulan dalam tiap tahun. Data dimulai dari Januari 2010 hingga Desember 2016. Dengan demikian dataset adalah 7 tahun atau 84 pengamatan. Metode yang digunakan dalam prediksi ini adalah Regresi LSTM dalam studi ini metode LSTM dapat dibawa ke dalam masalah regresi linear. Pengukur kriteria error yang digunakan adalah Root Mean Square Error (RMSE). Hasil prediksi training dengan menggunakan Regresi LSTM jika ditinjau dari nilai RMSE adalah 6529,42. Sementara itu hasil prediksi RMSE pada data testing adalah 13766,85.

Kedua, perbandingan metode yang dikembangkan untuk peramalan seri waktu yang dilakukan oleh Guang Zhang Xiaon, dkk. Penelitian tentang membandingkan kinerja dua dataset yaitu dataset tekanan pada listrik dan dataset penumpang pesawat yang digunakan sebagai tolak ukur untuk evaluasi algoritma [9]. Dataset yang digunakan adalah data yang dikumpulkan dari serangkaian waktu yang menggambarkan total bulanan penumpang maskapai internasional, yang mencakup 144 penelitian secara total selama 12 tahun. Pada dataset beban daya listrik berisi sampel konsumsi daya listrik setiap 15 menit. Pada penelitian ini dibagi beberapa algoritma skema LSTM untuk peramalan daya listrik. Membandingkan skema RNN berbasis LSTM yang diusulkan dengan metode SARIMA yang merupakan Seasonal Autoregressive Integrated Moving Average model. NARX yang mana adalah model jaringan saraf non linier autoregressive dengan eksogen input. SVR (Support Vector Regression) model yang sangat populer dalam peramalan deret waktu keuangan. Terakhir NNETAR yang merupakan model untuk peramalan deret waktu dengan layer tersembunyi dan input yang sebelumnya.

Dua kriteria evaluasi digunakan yaitu Root Mean Square Error (RMSE) dan Mean Absolute Percentage Error (MAPE) sebagai metrik kinerja antara nilai nyata dan hasil perkiraan. Hasil perbandingan lima algoritma untuk bagian dataset penumpang pesawat dengan skema LSTM memiliki nilai evaluasi RMSE 0,0435 dan MAPE 0,0345. Untuk SVR dengan RMSE 0.0717 dan MAPE 0.0556. NNETAR dengan RMSE 0.0799 dan MAPE 0.0595. NARX dengan RMSE 0.0452 dan MAPE 0.0403. SARIMA dengan RMSE 0,0359 dan MAPE 0,0256. Hasil perbandingan konsumsi daya listrik listrik dengan skema LSTM memiliki nilai evaluasi RMSE 0,0702 dan MAPE 0,0535. SVR dengan RMSE 0.2044 dan MAPE 0.1775 . NNETAR dengan RMSE 0.1955 dan MAPE 0.1689. NARX dengan RMSE 0.1446 dan MAPE 0.1192. SARIMA dengan RMSE 0,2537 dan MAPE 0,2001 [9]. 
Penelitian selanjutnya tentang Memristive Arsitektur perangkat keras pada LSTM Network untuk permasalah model time series predictive yang dilakukan oleh Kazybek Adam, dkk [10]. Penyelesaian masalah pada studi ini menggunakan metode Long Short Term Memory (LSTM). Dataset yang disediakan menunjukkan perubahan jumlah penumpang maskapai internasional selama periode 12 tahun dengan 144 titik pengamatan. Sebelum diproses, dataset dibagi menjadi dataset pelatihan dan dataset pengujian kemudian dinormalisasi antara 0 dan 1 karena sensitivitas LSTM untuk memasukkan data. Kumpulan data satu kolom dikonversi menjadi tiga kolom, di mana kolom pertama

\section{MATERIAL AND METHOD}

A. Dataset

Dataset didapatkan dari data penjualan obat "X" PT. Metiska Farma dengan jumlah data yang terkumpul sebesar 603 data. Data tersebut adalah data penjualan harian obat " $X$ " selama tiga tahun yaitu tahun 2017, 2018 dan 2019. Setiap instan data mengandung dua atribut, yaitu: tanggal dan nilai, dengan tanggal adalah tanggal penjualan perhari dan nilai adalah jumlah nilai rupiah dari penjualan berisi informasi pada jumlah penumpang di bulan sebelumnya. Kolom kedua berisi informasi jumlah penumpang pada bulan berjalan dan kolom ketiga adalah jumlah penumpang yang akan diprediksi. Perbandingan kinerja simulasi diperoleh dari perangkat lunak dan perangkat keras (analog). Hasil perbandingan mengungkapkan bahwa MSE dan RMSE untuk perangkat lunak prediksi masing masing adalah 0,0101 dan 0,1005. Sementara MSE dan RMSE untuk prediksi analog adalah 0,0121 dan 0,1099. Kesimpulan dari 461 total waktu simulasi rangkaian untuk memprediksi 45 titik uji adalah $3,96 \mathrm{~ms}$ dengan setiap siklusnya mengambil 88 detik.

obat " $X$ " per-harinya. Penggunaan jumlah nilai rupiah tujuannya adalah untuk memberikan informasi kepada dua bagian yaitu bagian produksi dan bagian marketing. Jika hanya nilai qty yang digunakan untuk prediksi maka, hanya untuk keperluan produksi yang dapat diketahui. Namun, bagian marketing tidak akan mendapatkan informasi seperti berapa nilai dalam rupiahnya. Penjelasan atribut instant data disajikan pada Tabel 1.

Table 1. Contoh Nilai Atribut Data

\begin{tabular}{ccc}
\hline No & Tanggal & Nilai \\
\hline 1 & $2017-04-01$ & $5,880,000$ \\
2 & $2017-04-03$ & $11,585,000$ \\
3 & $2017-04-04$ & $41,090,000$ \\
4 & $2017-04-05$ & $40,320,000$ \\
5 & $2017-04-06$ & $18,130,000$ \\
6 & $2017-04-07$ & $40,145,000$ \\
7 & $2017-04-08$ & $24,640,000$ \\
8 & $2017-04-10$ & $30,485,000$ \\
\hline
\end{tabular}


B. Tahapan Eksperimen

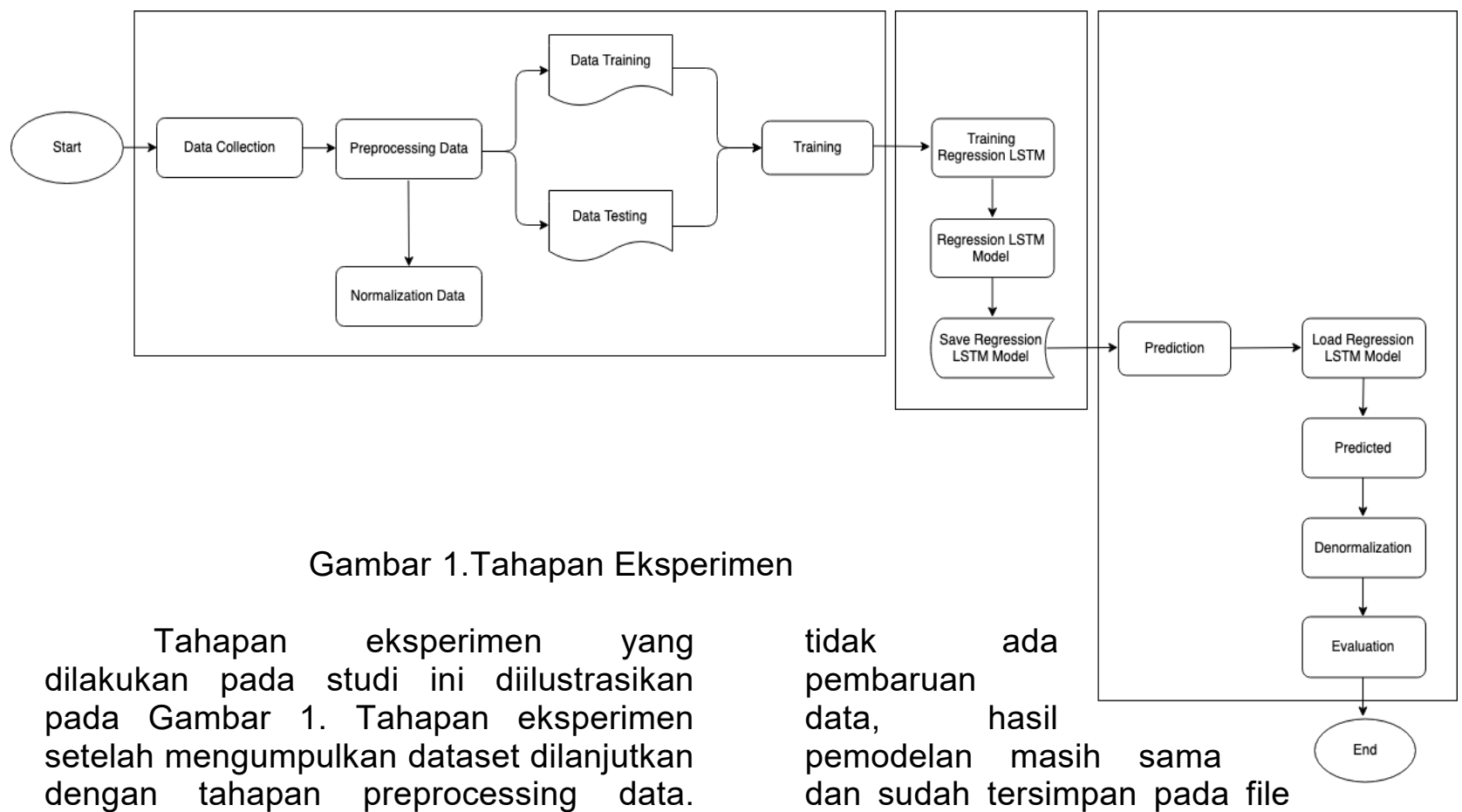

Tahap preprocessing data dilakukan dengan normalisasi terhadap dataset menggunakan min-max scaler dari scikit learn. Setelah tahap Preprocessing Data selesai dilakukan, tahap selanjutnya membagi dataset menjadi dua yaitu dataset training dan dataset testing. Setelah pembagian dataset, proses selanjutnya adalah proses training. File proses training dengan proses prediksi akan dipisah guna mendapatkan hasil prediksi yang pasti atau tidak berubah ubah. Tahap berikutnya dilanjutkan dengan pembuatan model dengan melakukan proses training Regresi Long Short Term Memory (LSTM).

Setelah proses pembuatan model Regresi LSTM selesai, maka model tersebut akan disimpan kedalam file HDF5 [11]. Di mana file HDF5 selanjutnya akan dimuat ke dalam proses prediksi. Tujuannya adalah ketika menjalankan proses prediksi tidak perlu menjalankan proses pembuatan model kembali jika tidak ada pembaruan data. Karena jika

HDF5 tersebut [12]. Setelah memuat model dari file HDF5, tahap selanjutnya adalah proses prediksi, dilanjutkan dengan proses denormalisasi. Tahap akhir adalah evaluasi kinerja model prediksi menggunakan RMSE dan MAPE dengan persentase antara data training dengan data testing.

C. Input Dataset

Dataset yang diinputkan telah dikonversi kedalam sebuah file csv (Comma Separated Values). Jumlah total dataset yang digunakan sebanyak 603 data, sesuai dengan data yang terkumpul. Dataset tersebut diatur komposisinya untuk data training dan data testing agar dapat diproses. Persentase komposisi dataset dibagi menjadi tiga, yaitu $70 \%$ untuk data training dan $30 \%$ untuk data testing. Kemudian dibentuk kembali komposisi dengan $80 \%$ untuk data training dan $20 \%$ untuk data testing. Komposisi terakhir, yaitu $90 \%$ untuk data training dan $10 \%$ untuk data testing. Tujuan pembagian komposisi tersebut adalah 
untuk mendapatkan metode pengujian terbaik.

D. Preprocessing Data

Preprocessing Data dalam studi ini meliputi normalisasi data. Data - data yang ada dilakukan normalisasi dengan membagi nilai data tersebut dengan nilai range data (nilai data maksimum - nilai data minimum) [13]. Data - data tersebut dinormalisasi ke dalam dua interval yaitu [$1,1]$ dan $[0,1]$ dengan tujuan memastikan interval mana yang menghasilkan nilai terbaik. Tujuan dari Normalisasi yaitu: 1. Untuk menghilang kerangkapan data. 2. Untuk mengurangi kompleksitas. 3. Untuk mempermudah melakukan modifikasi data.

$$
X_{n}=\frac{X_{0}-X_{\min }}{X_{\max }-X_{\min }}
$$

Keterangan:

$\mathrm{X} \mathrm{n}=$ Nilai hasil normalisasi

X_0 = Nilai data aktual

X_min = Nilai minimum dari data aktual

X_max $=$ Nilai maksimum dari data aktual

\section{E. LSTM Network for Regression}

Fungsi regresi diterapkan di banyak bidang, seperti pemulihan gambar, pengenalan pola, sistem kontrol dan identifikasi sistem. Fungsi regresi terutama untuk mendapatkan fungsi input - output set perkiraan yang diharapkan. Dalam sebagian besar aplikasi, fungsi ekspektasi sangat nonlinier dan sulit untuk mendapatkan formula secara akurat dalam matematika [4]. Regresi melakukan operasi pada dataset di mana nilai target telah ditentukan. Dan hasilnya dapat diperpanjang dengan menambahkan informasi baru [14]. LSTM dapat dibawa ke dalam masalah regresi linear. Prediksi dengan regresi akan menganalisa jumlah penjualan pada hari $t$ untuk memprediksi penjualan pada hari ke $t+1$.

Cara kerja Regresi LSTM yaitu dengan metode fungsi sederhana akan diberikan untuk mengkonversi kolom tunggal pada dataset menjadi kumpulan data dua kolom. Di mana kolom pertama berisi nilai penjualan pada hari ini (t) dan kolom kedua berisi nilai penjualan obat pada hari berikutnya $(t+1)$ [8]. Desain struktur jaringan LSTM, memiliki nilai output y $(t+1)$ adalah karakteristik satu dimensi nilai, output dirancang untuk menjadi satu. Dalam studi ini nilai input menggunakan window method [15]. LSTM memiliki arsitektur yang terdiri dari lapisan input, output, dan lapisan tersembunyi. Lapisan tersembunyi terdiri dari sel memori, satu sel memori memiliki tiga gate yaitu input gate, forget gate, output gate [16].

\section{F. Denormalisasi}

Output yang dihasilkan dari proses prediksi masih dalam bentuk data normalisasi, sehingga perlu dilakukan konversi menggunakan denormalisasi. Denormalisasi dilakukan untuk mengembalikan nilai atau data ke bentuk semula, sehingga hasil nilai atau data dari proses prediksi penjualan dapat dengan mudah dibaca dan dimengerti [17]. Setelah itu akan dihasilkan persentase data training dan data testing yang kemudian dapat dihitung error atau persentase errornya.

$$
\left.d n_{i}=\left(n_{i}+1\right)\left(x_{\max }-x_{\text {min }}\right)\right)+\left(\frac{2\left(x_{\min }\right)}{2}\right)
$$

Keterangan: 『dn】_i = Data hasil denormalisasi $n \_i=$ Data normalisasi $x \_$min $=$ Nilai minimum data real $x \_$max $=\overline{N i l a i}$ maksimum data real

\section{G. Evaluasi}

Studi yang dilakukan pada makalah ini kinerja model dievaluasi menggunakan RMSE (Root Mean Square Error) dan MAPE (Mean Absolute Percentage Error). RMSE adalah aturan penilaian kuadrat yang juga mengukur besarnya rata - rata kesalahan. RMSE merupakan akar kuadrat dari rata - rata perbedaan kuadrat antara prediksi dan observasi aktual dari sebuah data. Berikut rumus dari RMSE adalah

$$
\mathrm{RMSE}=\sqrt{\frac{\sum_{t=0}^{T}\left(y^{\wedge} t-y t\right)^{2}}{\mathrm{~T}}}
$$


Metode lain untuk mengevaluasi metode peramalan adalah Mean Absolute Percentage Error (MAPE). MAPE dihitung dengan menggunakan kesalahan absolut pada tiap periode, dibagi dengan nilai observasi yang nyata. Berikut rumus dari MAPE adalah

$$
\text { MAPE }=\frac{100}{T} \sum_{t=0}^{T}\left|\frac{\left(y t-y^{\wedge} t\right)}{y t}\right|
$$

Dengan keterangan di mana $\mathrm{t}=$ periode waktu, $\mathrm{T}=$ jumlah total pengamatan, $\mathrm{yt}=$ nilai aktual dan $\mathrm{y}^{\wedge} \mathrm{t}=$ nilai perkiraan pada waktu adalah t. Untuk semua kriteria evaluasi, semakin kecil ukuran nilai kesalahan mengindikasikan semakin baik model yang diterapkan. Dan MAPE digunakan untuk mengoptimalkan kesalahan dari nilai aktual [18].

\section{HASIL DAN DISKUSI}

Pelaksanaan tahap uji coba perangkat lunak ini didefinisikan parameter yang digunakan seperti perubahan epoch, perubahan range, dan perubahan look back. Proses uji coba dilakukan untuk menentukan keakuratan sistem dalam melakukan proses prediksi penjualan berdasarkan parameter yang tersedia. Definisi parameter disajikan pada Tabel 2 dan pembagian skenario eksperimen untuk proses training dan prediksi disajikan pada Tabel 3

Tabel 2. Definisi Parameter

\begin{tabular}{cccc}
\hline Parameter & 1 & 2 & 3 \\
\hline Dataset (D) & $70 / 30$ & $80 / 20$ & $90 / 10$ \\
Range (R) & {$[0,1]$} & {$[-1,1]$} & \\
$\begin{array}{c}\text { Look Back } \\
(\mathrm{L})\end{array}$ & 1 & 2 & 3 \\
\hline
\end{tabular}

Tabel 3. Skenario Eksperimen

\begin{tabular}{cc}
\hline Skenario & Keterangan \\
\hline 1 & D1, R1, L1 \\
2 & D1, R1, L2 \\
3 & D1, R1, L3 \\
4 & D1, R2, L1 \\
5 & D1, R2, L2 \\
6 & D1, R2, L3 \\
7 & D2, R1, L1 \\
8 & D2, R1, L2 \\
9 & D2, R1, L3 \\
10 & D2, R2, L1 \\
11 & D2, R2, L2 \\
12 & D2, R2, L3 \\
13 & D3, R1, L1 \\
14 & D3, R1, L2 \\
15 & D3, R1, L3 \\
16 & D3, R2, L1 \\
17 & D3, R2, L2 \\
18 & D3, R2, L3 \\
\hline
\end{tabular}


Skenario eksperimen dibuat dengan tujuan untuk mendapatkan metode prediksi terbaik dari parameter yang tersedia. Pada Tabel 3 yang telah disajikan dapat dilihat ada delapan belas kali percobaan prediksi dalam mencari metode terbaik untuk memprediksi penjualan pada studi ini. Melalui evaluasi kinerja model menggunakan RMSE dan MAPE hasil dari delapan belas eksperimen tersebut disajikan dalam Tabel 4.

\begin{tabular}{|c|c|c|c|c|c|}
\hline Skenario & Keterangan & $\begin{array}{l}\text { RMSE } \\
\text { Training }\end{array}$ & RMSE Testing & MAPE Training & MAPE Testing \\
\hline 1 & D1, R1, L1 & 303.463 .052 & 228.180 .628 & $771 \%$ & $345 \%$ \\
\hline 2 & D1, R1, L2 & 296.818 .680 & 234.714 .480 & $1127 \%$ & $481 \%$ \\
\hline 3 & D1, R1, L3 & 298.615 .562 & 233.848 .093 & $806 \%$ & $376 \%$ \\
\hline 4 & D1, R2, L1 & 301.771 .519 & 234.025 .598 & $1320 \%$ & $547 \%$ \\
\hline 5 & D1, R2, L2 & 299.881 .134 & 233.025 .941 & $1018 \%$ & $443 \%$ \\
\hline 6 & D1, R2, L3 & 299.567 .286 & 231.717 .635 & $1193 \%$ & $484 \%$ \\
\hline 7 & D2, R1, L1 & 297.321 .103 & 205.473 .604 & $873 \%$ & $357 \%$ \\
\hline 8 & $\mathrm{D} 2, \mathrm{R} 1, \mathrm{~L} 2$ & 295.443 .414 & 206.923 .892 & $640 \%$ & $290 \%$ \\
\hline 9 & D2, R1, L3 & 293.662 .875 & 208.573 .128 & $957 \%$ & $376 \%$ \\
\hline 10 & D2, R2, L1 & 297.478 .325 & 209.533 .577 & $1163 \%$ & $446 \%$ \\
\hline 11 & D2, R2, L2 & 297.043.058 & 209.432 .702 & $905 \%$ & $357 \%$ \\
\hline 12 & D2, R2, L3 & 296.550 .435 & 209.357 .600 & $993 \%$ & $382 \%$ \\
\hline 13 & D3, R1, L1 & 291.176 .168 & 194.591 .737 & $1277 \%$ & $515 \%$ \\
\hline 14 & D3, R1, L2 & 288.861 .891 & 191.864 .454 & $1187 \%$ & $441 \%$ \\
\hline 15 & D3, R1, L3 & 286.465 .424 & 187.013 .430 & $787 \%$ & $309 \%$ \\
\hline 16 & D3, R2, L1 & 289.920 .002 & 189.482 .599 & $1065 \%$ & $424 \%$ \\
\hline 17 & D3, R2, L2 & 292.470 .066 & 196.833.285 & $1383 \%$ & $500 \%$ \\
\hline 18 & D3, R2, L3 & 299.942 .541 & 188.354 .835 & $873 \%$ & $278 \%$ \\
\hline
\end{tabular}

Tabel 4. Hasil RMSE dan MAPE Regresi LSTM

Dari hasil delapan belas eksperimen yang telah dilakukan, dapat diketahui bahwa eksperimen kelima belas mempunyai nilai RMSE yang paling rendah. Dengan begitu metode terbaik dari skenario eksperimen yang tersedia, eksperimen 
kelima belas adalah eksperimen yang terbaik. Nilai evaluasi kinerja model yang dihasilkan oleh eksperimen kelima belas melalui RMSE adalah 286.465.424 untuk data training dan 187.013.430 untuk data testing. Evaluasi melalui MAPE untuk eksperimen kelima belas memiliki nilai $787 \%$ untuk data training dan $309 \%$ untuk data testing. Nilai - nilai tersebut adalah nilai rata - rata total RMSE dan MAPE dari seluruh data instan yang ada. Plot hasil eksperimen kelima belas dapat dilihat pada Gambar 2

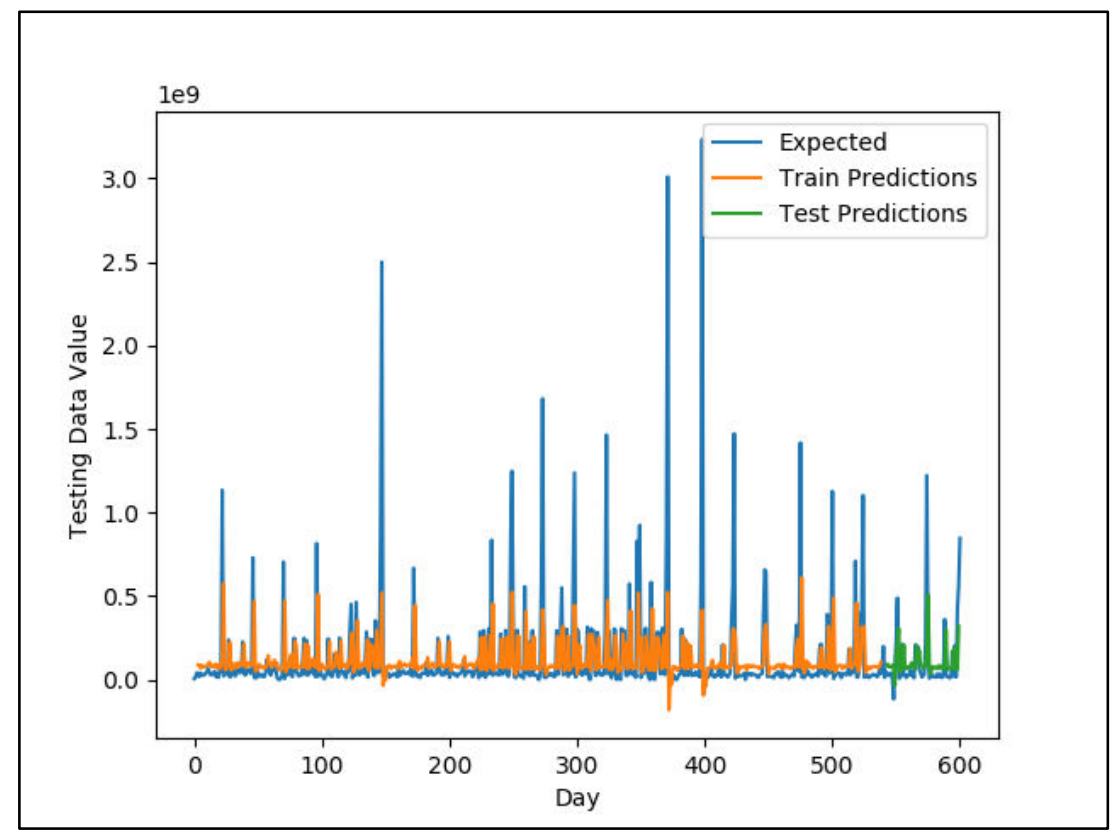

Gambar 2. Plot Hasil Eksperimen Kelima Belas

\section{KESIMPULAN}

Dalam studi ini, Regresi Long Short Term Memory (LSTM) diimplementasikan pada dataset penjualan obat "X" PT. Metiska Farma untuk memprediksi penjualan di masa depan. Berdasarkan hasil skenario percobaan, percobaan kelima belas adalah percobaan yang terbaik karena memiliki nilai RMSE terendah. Hasil penelitian ini menunjukkan bahwa uji coba kelima belas merupakan metode terbaik untuk Regresi LSTM. Dengan komposisi data latih $90 \%$ dan data uji $10 \%$, range interval $[0,1]$, look back atau window method sebanyak tiga dan epoch sebanyak 100. Metode tersebut mendapatkan hasil evaluasi model melalui RMSE sebesar 286.465.424 untuk data training dan 187.013 .430 untuk data testing. Metode kelima belas juga mendapatkan MAPE sebesar $787 \%$ dan $309 \%$ untuk data training dan data testing secara berurut. Dalam studi selanjutnya, kami akan mengeksplorasi beberapa peluang untuk menerapkan teknik yang lain dalam domain ini dan dapat membangun model lainnya

\section{REFERENSI}

[1] R. A. Juanda, Jondri, and A. A. Rohmawati, "Prediksi Harga Bitcoin Dengan Menggunakan Recurrent Neural Network," e-Proceeding Eng., vol. 5, no. 2, pp. 3682-3690, 2018.

[2] N. K. M. T. Okwara, "Sistem Peramalan Dan Monitoring Persediaan Obat Di Rspg Cisarua Bogor Dengan Menggunakan Metode Single Exponential Smoothing Dan Reorder Point," J. IIm. Komput. dan Imformatika, pp. 45-52, 2013.

[3] C. S. Hsu and J. R. Jiang, "Remaining useful life estimation using long short- 
term memory deep learning," Proc. 4th IEEE Int. Conf. Appl. Syst. Innov. 2018, ICASI 2018, pp. 58-61, 2018.

[4] S. Li, H. Fang, and B. Shi, "Multi-StepAhead Prediction with Long Short Term Memory Networks and Support Vector Regression," Chinese Control Conf. CCC, vol. 2018-July, pp. 81048109, 2018.

[5] J. Tian and X. Zhao, "Apply multiple linear regression model to predict the audit opinion," 2009 Second ISECS Int. Colloq. Comput. Commun. Control. Manag. CCCM 2009, vol. 4, pp. 303-306, 2009.

[6] J. Nangi et al., "Peramalan Persediaan Obat Menggunakan Metode Triple Exponential Smoothing (Tes) (Studi Kasus: Instalasi Farmasi Rsud Kab. Muna)," semanTIK, vol. 4, no. 1, pp. 135-142, 2018.

[7] Y. Liu, Y. Qin, J. Guo, C. Cai, Y. Wang, and L. Jia, "Short-term forecasting of rail transit passenger flow based on long short-term memory neural network," 2018 Int. Conf. Intell. Rail Transp. ICIRT 2018, pp. 1-5, 2019.

[8] A. A. Rizal and S. Soraya, "Multi Time Steps Prediction dengan Recurrent Neural Network Long Short Term Memory," MATRIK J. Manajemen, Tek. Inform. dan Rekayasa Komput., vol. 18, no. 1, pp. 115-124, 2018.

[9] Xiao-Guang Zhang, Yi-Min Li, Shi-Jin Ren, and Ji-Hua Xu, "Robust wavelets support vector machine estimation method for regression," no. August, pp. 998-1003 Vol. 2, 2005.

[10] K. Adam, K. Smagulova, and A. P. James, "Memristive LSTM network hardware architecture for time-series predictive modeling problems," 2018 IEEE Asia Pacific Conf. Circuits Syst. APCCAS 2018, pp. 459-462, 2019.

[11] R. Bhowmik, J. Hartog, and M. Govindaraju, "Processing HDF5 datasets on multi-core architectures," Proc. - Int. Conf. Adv. Inf. Netw. Appl. AINA, pp. 666-673, 2013.

[12] N. P. Sakinah, I. Cholissodin, and A. W. Widodo, "Prediksi Jumlah Permintaan Koran Menggunakan
Metode Jaringan Syaraf Tiruan Backpropagation," J. Pengemb. Teknol. Inf. dan IImu Komput. Univ. Brawijaya, vol. 2, no. 7, pp. 26122618, 2017.

[13] R. Hidayat, "Meminimalisasi nilai error peramalandengan algoritma," pp. 187-192, 2012.

[14] D. Bhuriya, G. Kaushal, A. Sharma, and U. Singh, "Stock market predication using a linear regression," Proc. Int. Conf. Electron. Commun. Aerosp. Technol. ICECA 2017, vol. 2017-Janua, pp. 510-513, 2017.

[15] Z. Chen, Y. Liu, and S. Liu, "Mechanical state prediction based on LSTM neural netwok," Chinese Control Conf. CCC, pp. 3876-3881, 2017.

[16] R. Vinayakumar, K. P. Soman, and P. Poornachandran, "Long short-term memory based operation log anomaly detection," 2017 Int. Conf. Adv. Comput. Commun. Informatics, ICACCI 2017, vol. 2017-Janua, pp. 236-242, 2017.

[17] J. I. Matematika and S. D. Anggraini, "PREDIKSI NILAI TUKAR MATA UANG ASING MENGGUNAKAN EXTREME LEARNING MACHINE," J. IIm. Mat. ISSN 2301-9115, vol. 3, no. 6, pp. 110-115, 2017.

[18] S. Ahmad and H. A. Latif, "Forecasting on the crude palm oil and kernel palm production: Seasonal ARIMA approach," 2011 IEEE Colloq. Humanit. Sci. Eng. CHUSER 2011, vol. 2, no. Chuser, pp. 939-944, 2011. 